TABLE I

Assessment of clinical posts by trainees

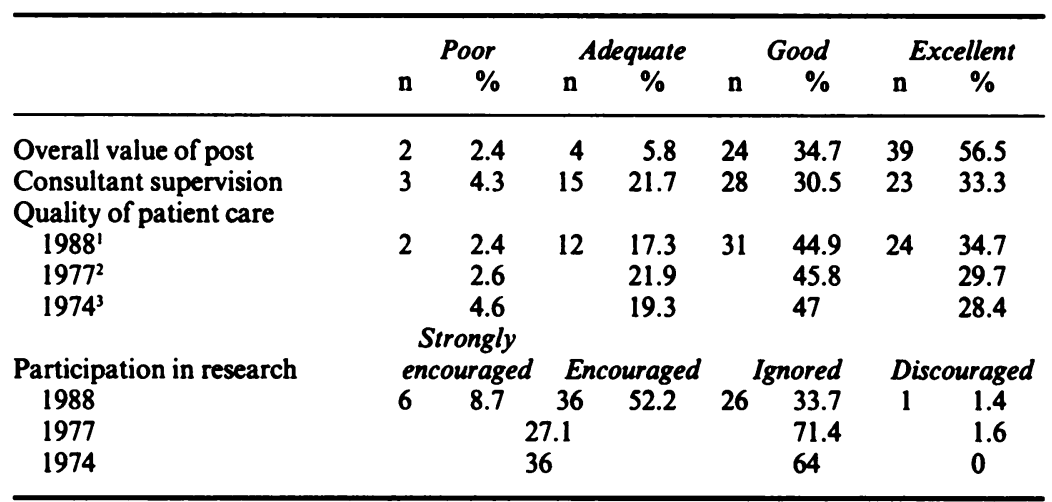

1. Current study.

2. Creed \& Murray, 1981.

3. Jeffreys \& Murray, 1976.

\section{Psychiatric training at the Maudsley Hospital}

DeAr SirS

The above table was omitted from the published version of our paper 'Psychiatric Training at the Maudsley Hospital: A Survey of Junior Psychiatrists' (Psychiatric Bulletin, May 1990, 14, 289-292). The table displays the results of a survey of Maudsley Hospital SHOs and registrars and compares results with two previous surveys (Creed \& Murray, 1981; Jeffreys \& Murray, 1976).

THOMAS FAHY

Institute of Psychiatry

London SE5 8 AF

\section{References}

CReEd, F. \& MURRAY, R. M. (1981) The teaching of clinical skills at a postgraduate hospital. Psychological Medicine. 11, 391-399.

JefFreYs, P. M. \& MURRAY, R. M. (1976) Trainees' assessment of vocational training in psychiatry: a pilot study at the Maudsley Hospital. Medical Education, 10, 52-55.

\section{Patients' participation in examinations \\ DeAR SIRS}

In response to the letter by Dr Lynch (Psychiatric Bulletin, May 1990, 14, 308) concerning the adverse effects on the mental state of patients participating in examinations, I can only write to agree. I was recently involved as organiser of the MRCPsych Part I examinations in Newcastle, and noted a number of responses among our patients. One group seemed positively to enjoy the experience, two patients being so pleased to be of help that they donated their $£ 8$ fee to the hospital cancer research fund. A small group, however, were quite badly affected; one man with schizo-affective disorder became markedly anxious and rather paranoid, a depressed lady (after being very enthusiastic) somatised her distress and withdrew with back pain, while another obsessional man broke down somewhat after interview and began to experience depressive and suicidal feelings we had previously successfully controlled.

I found that the best methods for dealing with the distress which largely resulted from anticipatory anxiety, the tense atmosphere of examinations and boredom, were the well tried diversionary activity provided by nurses in attendance, a portable television, and a steady supply of cigarettes.

Another interesting point was the effect on the mental state of those organising and running the exam, which seemed to veer between depressive despondency ("none of the patients will turn up"), manic denial ("who cares!"), and a particularly nasty obsessionality, evoked when trying to keep the exams running smoothly.

\section{Hadrian Clinic}

S. R. HUMPHRIES

Newcastle General Hospital

Westgate Road

Newcastle upon Tyne NE4 4XT

\section{The double negatives and the Mental Health Review Tribunal}

DeAr Sirs

As lay and medical members of the Mental Health Review Tribunal we are interested in the letter from 